\title{
Animism and Language Evolution
}

\author{
Eldar T. Hasanov
}

\begin{abstract}
The exact mechanism of the evolution of language remains unknown. One of the central problems in this field is the issue of reliability and deceit that can be characterized in terms of honest signaling theory. Communication systems become vulnerable to dishonesty and deceit when there are conflicting interests between the signaler and receiver. The handicap principle explains how evolution can prevent animals from deceiving each other even if they have a strong incentive to do so. It suggests that the signals must be costly in order to provide accurate and reliable communication between animals. Language-like communication systems, being inherently vulnerable to deception, could only evolve and become evolutionarily stable if they had some mechanisms that can make the communication hard to fake and trustworthy. One of the theories that try to solve the problem of reliability and deception is the ritual/speech coevolution hypothesis. According to this theory, hard-to-fake rituals evolved concurrently with language - by reinforcing trust and solidarity among early humans and preventing deceitful and manipulative behavior within the group. One of the drawbacks of this hypothesis is that the relationship between ritual and speech is too indirect. Rituals could not have a real-time effect on every instance of speech and encompass all aspects of everyday language communication. Therefore they are not efficient enough to provide instant verification mechanisms to guarantee honest communication. It is more likely that the animistic nature of language itself, rather than ritual, was the handicap-like cost that helped to ensure the reliability of language during its origin. The belief in the parallel dimension of animistic spirits emerged concurrently with language as a hard-to-fake attestation mechanism that ensured inviolability of one's speech. The notion that the animism emerged because of early behaviorally modern humans' incoherent and flawed observations about the natural world is unlikely, because it implies a very improbable scenario, that there had been a more coherent and rational pre-animistic period which later degraded to animistic one.
\end{abstract}


The exact mechanism of the evolution of language remains unknown. One of the central problems in this field is the issue of reliability and deceit that can be characterized in terms of honest signaling theory. Animal communication systems are shaped by mutual interests between signalers and receivers. When there are conflicting interests between signalers and receivers, communication systems become vulnerable to dishonesty and deceit making them evolutionarily unstable. Alternative mutant strategies that are based on manipulative behavior can challenge and replace it. ${ }^{1}$ Any individuals within the group, who evolve to become better at manipulating signal receivers, can develop a fitness advantage over the other group members, obstructing the development of the communication system. For a strategy to be evolutionarily stable, along with increasing fitness, it must have built-in mechanisms that prevent alternative strategies which give competitors higher fitness. If providing false signals and exploiting the signaling system would be in their genes' interests then by having this reproductive benefit they will raise, on average, more offspring than the other group members, and will ultimately replace them. ${ }^{2}$ As a result, signalers evolve to become better at manipulating receivers, while receivers evolve to become more resistant to manipulation. ${ }^{4}$ Every dishonest signal weakens the integrity of the communication system, reducing or even cutting short its evolutionary advantages. In order for a signaling system to be evolutionarily stable, the transfer of information between group members should be reliable and resistant to falsification. The handicap principle explains how evolution can prevent animals from deceiving each other even if they have a strong incentive to do so. ${ }^{5}$ It suggests that the signals must be costly in order to provide accurate and reliable communication between animals. For example, the excessive tails of peacocks serve as the evolutionary cost that validates their overall fitness. ${ }^{6}$ It is hard to fake because peacocks having oversized tails without the necessary fitness to maintain it, will not survive.

The same factors of reliability and deception can block the development of more sophisticated and efficient language-like signaling systems because unrestrained associations of sounds and other signals with corresponding meanings are unreliable and may easily be manipulated. Deceptive behavior has been observed among primates in both natural and experimental conditions. At the same time primates

\footnotetext{
1 Maynard Smith, John (1982). Evolution and the Theory of Games. ISBN 0-521-28884-3.

2 Dawkins, Richard (1995). River Out of Eden: A Darwinian View of Life. Science Masters Series. New York: Basic Books. ISBN 978-0-465-016068. LCCN 94037146. OCLC 31376584.

3 Pinker, S. (2012). The False Allure of Group Selection. Edge, Jun 19, 2012.http://edge.org/conversation/the-false-allure-of-group-selection

4 Dawkins, Richard; Krebs, John (1978). Krebs, John; Davies, N. B. (eds.). Animal signals: information or manipulation?. Behavioural Ecology: an evolutionary approach. Blackwell. pp. 282-309.

5 Zahavi, Amotz (1975). "Mate selection-A selection for a handicap". Journal of Theoretical Biology. Elsevier BV. 53 (1): $205-214$. doi:10.1016/0022-5193(75)90111-3. ISSN 0022-5193. PMID 1195756.

${ }^{6}$ Caldwell, Roy, and Jennifer Collins. "When Sexual Selection Runs Away Archived29 November 2014 at the Wayback Machine." Evolution $101:$ Runaway Selection. N.p., n.d. 24 November 2014.
} 
remain constantly alert against other group members who may attempt to deceive them. ${ }^{7}$ These examples include deliberately and falsely attributing blame to another individual in order to redirect blame from oneself, using false warning screams for diverting other group members from food sources ${ }^{8}$, exaggerated "looking" gesture which in an honest context would warn about predator. ${ }^{9}$ In experimental conditions some primates, that have been trained to use sign language, used it in an attempt to deceive human observers. ${ }^{10}$

Using a language-like communication system involves a great risk of deception, so it could only be evolutionarily stable if there were some mechanisms that made the signaling system hard to fake and trustworthy. ${ }^{11}$ Animal vocal signals have a limited number of elements and they are hard to fake because they directly reflect the animal's current state, for example growling represents an aggressive warning that makes it an intrinsically honest signal. On the other hand, language represents the arbitrary associations of sounds with corresponding meanings so it may be easily falsified. ${ }^{12}$ Unlike animal vocal signals, language can communicate about things that are remote in space or time giving human ancestors the ability to take communication out of the "here" and "now". This makes it even more prone to deception as the information about things, that are not immediately spatially or temporally present, is not easily verifiable.

The primates' use of deception and resulting resistance to deception can block the evolution of language. ${ }^{13}$ Without an additional mechanism guaranteeing its reliability language could not have evolved. In order to avoid being deceived primates will ignore all signals that are not directly verifiable. For language to work, then, listeners must be confident that speakers are honest. ${ }^{14}$

One of the theories that try to explain how human ancestors could begin trusting cheap signals in ways that other primate apparently cannot and is the ritual/speech coevolution hypothesis. This theory attempts to clarify the origins of extraordinarily high levels of deliberate honesty required for language to develop.

\footnotetext{
7 Byrne, Richard W.; Whiten, Andrew. (1988). Machiavellian intelligence : social expertise and the evolution of intellect in monkeys, apes, and humans. Oxford: Clarendon Press. ISBN 978-0-19-852175-4. OCLC 17260831.

8 Wheeler, Brandon (2009). "Monkeys crying wolf? Tufted". Proceedings. Biological Sciences. 276 (1669): 3013-3018. doi:10.1098/rspb.2009.0544. PMC 2817219. PMID 19493903

9 Byrne, Richard; Whiten (1985). "Tactical deception of familiar individuals in baboons (Papio ursinus)". Animal Behaviour. 33 (2): $669-673$. doi:10.1016/s0003-3472(85)80093-2. S2CID 53186497.

${ }^{10}$ Green, Malcom (2005). Book of Lies (1st ed.). Kansas City: Andrews McMeel Publishing. p. 61. ISBN 9780740755606.

${ }^{11}$ Knight, C. 1998. Ritual/speech co-evolution: a solution to the problem of deception. In J. R.

Hurford, M. Studdert-Kennedy and C. Knight (eds), Approaches to the Evolution of Language: Social and cognitive bases. Cambridge: Cambridge University Press, pp.68-91.

12 Zahavi, A. (May 1993). "The fallacy of conventional signalling". Philosophical Transactions of the Royal Society B: Biological Sciences. 340 (1292): 227-230. Bibcode:1993RSPTB.340..227Z. doi:10.1098/rstb.1993.0061. PMID 8101657.

${ }^{13}$ Knight, Chris (1998). James R Hurford; Michael Studdert-Kennedy; Chris Knight (eds.). Ritual/speech coevolution: a solution to the problem of deception (PDF). Approaches to the evolution of language : social and cognitive base. Cambridge, UK; New York: Cambridge University Press. pp. 68-91. ISBN 978-0-521-63964-4. OCLC 37742390.

${ }^{14}$ Power, Camilla (1998). James R Hurford; Michael Studdert-Kennedy; Chris Knight (eds.). Old wives' tales: the gossip hypothesis and the reliability of cheap signals. Approaches to the evolution of language : social and cognitive base. Cambridge, UK; New York: Cambridge University Press. pp. 111-129. ISBN 978-0-521-63964-4. OCLC 37742390.
} 
According to this theory, hard-to-fake rituals evolved concurrently with language - by reinforcing trust and solidarity among early humans and preventing deceitful and manipulative behavior within the group. ${ }^{15},{ }^{16}$

The major drawback of this theory is that the relationship between ritual and speech is too indirect. Even though rituals can enhance trust and solidarity in a community, ${ }^{17}$ they could not have an immediate effect on every instance of speech and encompass all aspects of everyday language communication. That is why it is not efficient enough to provide an instant verification mechanism to guarantee honest communication.

It is more likely that the animistic nature of language itself, rather than ritual, was the handicap-like cost that helped to ensure the reliability of language. The attribution of spiritual essence to everything surrounding early humans served as a built-in mechanism that provided instant verification and ensured the inviolability of one's speech.

Animism is the belief that all natural things, such as plants, animals, rocks, thunder, have spirits. Even things like a person's or animal's shadow, breath, blood, liver, heart, or eye have their own spiritual essence. ${ }^{18}$ The notion that the animistic stage in history emerged because of early behaviorally modern humans incoherent and flawed observations about the natural world is improbable because it implies very unlikely scenario that there had been a more coherent and rational pre-animistic period in human history that later degraded to animistic phase. During the evolution of language, the belief in the parallel dimension of animistic spirits emerged concurrently with language as a hard-to-fake attestation mechanism that aided information exchange in the human society by sacralizing relationship between words and things they refer to and making this relationship less arbitrary. The emergence of animism may be explained as a result of costly adaptation promoted by natural selection alongside language.

Words describing surrounding objects emerged together with the parallel dimension of spirits attached to them that served as validating agents, which instantly verified communication between individuals in realtime. The closest approximation of prehistoric animistic mindset and speech to modern one could be taking an oath invoking a divine witness. Similar to animistic language, an oath represents utterance with wording relating to something considered sacred as a sign of the truth. The fundamental nature of both animistic speech and an oath is an invocation of divine agency to be a guarantor of honesty and integrity of communication by creating the feeling of deep respect and veneration. Even nowadays some religious

\footnotetext{
${ }^{15}$ Rappaport, Roy (1999). Ritual and religion in the making of humanity. Cambridge, U.K. New York: Cambridge University Press. ISBN 9780521296908. OCLC 848728046.

${ }^{16}$ Knight, Chris (1998). James R Hurford; Michael Studdert-Kennedy; Chris Knight (eds.). Ritual/speech coevolution: a solution to the problem of deception (PDF). Approaches to the evolution of language : social and cognitive base. Cambridge, UK; New York: Cambridge University Press. pp. 68-91. ISBN 978-0-521-63964-4. OCLC 37742390 ${ }^{17}$ Irons, W. (1996). J. P. Hurd (ed.). Morality as an Evolved Adaptation. Investigating the Biological Foundations of Morality. Edwin Mellon Press. pp. 1-34

${ }^{18}$ Bailey L.W. (2010) Animism. In: Leeming D.A., Madden K., Marlan S. (eds) Encyclopedia of Psychology and Religion. Springer, Boston, MA. https://doi.org/10.1007/978-0-387-71802-6_32
} 
groups refuse to swear oaths believing that taking oath implies different standards of truth with and without oaths.

According to handicap theory, if a signal is to remain reliable, and generally resistant to falsification, the signal has to be evolutionarily costly. ${ }^{19}$ Signaling systems often evolve not to be efficient but, on the contrary, to be complicated, wasteful, and energy-consuming. This can explain the elaborate and wasteful nature of animistic language. The alternate reality of spirits is superfluous and unnecessary for communication purposes. Its main function is to strengthen the reliability of language and facilitate its evolution.

By attributing spiritual agency to all things around them-animals, trees, caves, weather systems, human handiwork, and all other objects, places, and creatures - animism added hard-to-fake cost to signaling communication. Animism acted as the handicap maintaining honesty in the signaling system where signaler and receiver have non-identical interests. Although animistic worldview partially distorted the shape of reality and deliberately presented information in an inaccurate and intricate manner, it simultaneously promoted truth-conducive behavior which guaranteed inherently honest language communication. The higher the advantages of a new communication system are, the higher evolutionary costs, that make this communication system reliable, can grow. ${ }^{20}$ So the evolutionary benefits of language exceeded the costs associated with animism's distortion of reality and its wastefulness related to presenting information in an erroneous and obscure way.

The hypothesis is based on the following additional arguments.

First, the universality of animism among early modern humans and indigenous people living across the world from tropical rainforest to arctic tundra points to its deep evolutionary past.

Second, the absence of any evidence of preanimistic belief systems among prehistoric societies and modern hunter-gatherers may suggest there was no preanimistic period in behaviorally modern humans' history at all and animism evolved concurrently with language by facilitating its development.

Third, it can explain the origin of animism itself. Animism, representing a purposeful distortion of logical expectations about the nature of the world, could not have emerged without strong underlying driving forces. Rather than being pejoratively viewed as a wasteful error resulting from ignorance and blindly accepted irrational beliefs among early humans and indigenous people, animism should be viewed as being instrumental in ensuring the trustworthiness of communication during the evolution of language. In many respects, it is more coherent and consistent than the consequent post-animistic worldview based on sacred-profane dichotomy.

\footnotetext{
${ }^{19}$ Grafen, A. (1990). "Biological signals as handicaps". Journal of Theoretical Biology. 144 (4): 517-546. doi:10.1016/S0022-5193(05)80088-8. PMID 2402153.

${ }^{20}$ Zahavi, Amotz (1977). "The cost of honesty". Journal of Theoretical Biology. Elsevier BV. 67 (3): 603-605. doi:10.1016/0022-5193(77)900613. ISSN 0022-5193. PMID 904334.
} 
Since an animistic worldview is based on the belief that all material phenomena have numinous power and reality is identical with divinity, any attempts to falsify and misrepresent a given reality can invoke divine anger and condemnation. C.S. Lewis explains the numinous with the following example. Suppose you were told there was a tiger in the next room: you would know that you were in danger and would probably feel fear. But if you were told "There is a ghost in the next room," and believed it, you would experience a different kind of feeling - one that inspires awe and reverence. ${ }^{21}$ Although the feeling of fear is common to both humans and animals, awe-inspiring numinous feelings can be experienced only by humans.

Unlike costly honest signaling systems in nature, the physiological costs of spoken language are minimal and not enough to make signals reliable. That is why the innate psychological costs having awe-inspiring, truth-conductive and ego-suppressing effects co-evolved as a handicap ensuring the evolution of honest language communication. This can explain why evolution selected for ostensibly maladaptive and counterintuitive traits that have no clear benefit for the human's fitness and survival such as ones that obscure the clarity of ideas and speech and violate the principles of the natural world.

Humans, being biologically programmed to impute intentions to inanimate forces from the weather, to waves and currents, to falling rocks ${ }^{22}$ have a number of cognitive biases that previously channeled spiritual beliefs into animistic form. Although the development of human civilization weakens its links with its animistic past, many aspects of it nevertheless reassert themselves in different forms. One way in which this manifested is anthropomorphism - an innate human tendency to attribute human traits, emotions, or intentions to non-human entities like animals, inanimate objects, and even natural forces, such as seasons and weather. ${ }^{23}$ It characterizes objects, and abstract concepts as possessing humanlike traits, emotions, and intentions. It is a major part of human culture and anthropomorphic characters appear all the way through human history from ancient myths to modern movies. According to child development studies, children were born with an innate animist worldview in which they anthropomorphized inanimate objects. ${ }^{24}$

Deaf people, who learned sign language later during their lives, describe their pre-language thinking as showing some animistic patterns, for example attributing life to inanimate objects like the moon. ${ }^{25}{ }^{26}$

\footnotetext{
21 Lewis, C.S. (2001) [1940]. The Problem of Pain, pp. 5-6, Grand Rapids, MI, USA: Zondervan, ISBN 0060652969, see [1], accessed 19 October 2015.

22 Dawkins, Prof. Richard(2006) The God Delusion. Published by Bantam Press, Transworld Publishers, Uxbridge Road, London, UK. A hardback book. P183

23 Hutson, Matthew (2012). The 7 Laws of Magical Thinking: How Irrational Beliefs Keep Us Happy, Healthy, and Sane. New York: Hudson Street Press. pp. 165-81. ISBN 978-1-101-55832-4.

24 Harvey, Graham (2006). Animism: Respecting the Living World. Columbia University Press. p. 9. ISBN 978-0-231-13700-3.

25 Documents of the Assembly of the State of New York, Volume 2 By New York (State). Legislature. P.21 https://books.google.com/books?id=WOYbAQAAIAAJ\&newbks=0\&printsec=frontcover\#v=onepage \&q\&f=false

${ }^{26}$ William James Source: The Philosophical Review, Nov., 1892, Vol. 1, No. 6 (Nov., 1892), pp. 613-624 Published by: Duke University Press on behalf of Philosophical Review Stable URL: https://www.jstor.org/stable/2175920
} 
Other examples of inclination to conclude that events are caused by intelligent entities in situations that do not involve one and a tendency to search for meaningful connections between unrelated things include widely held beliefs in good or bad luck, lucky and unlucky symbols, signs, amulets, mascots, fortunetelling, astrology and claimed abilities to use extrasensory perception to identify information hidden from the normal senses.

A belief in the transcendent qualities of words is reflected in the close connection between language and magic. ${ }^{27}$ Adherents of magic believe in their ability to manipulate supernatural beings and forces by using incantations, spells, charms enchantments, etc. The performance of magic almost always involves the use of language and even stage magic often accompanied with some incantation words and phrases. Whether spoken out loud or unspoken, words are frequently used to access or guide transcendent power. Using spoken or silent mantras is an integral part of many meditation techniques. It aids concentration in meditation even when mantra words or sounds do not have any literal meaning.

These examples show that along with, its primary function - communication, language has collectivelyinherited and universally present spiritual aspect ${ }^{28}$ and both of these closely related aspects co-evolved together.

The predisposition for honest communication among early animistic humans may have contributed to the origin of the idealized concept of the noble savage. This concept existed as early as during the time of the Epic of Gilgamesh, where he appears as Enkidu. It represents an uncivilized man, who symbolizes the intrinsic integrity of one not exposed to the corrupting influences of civilization.

Another way in which the genetic predisposition for honest communication manifests itself is the fact that deception requires deliberate conscious behavior and causes some physiological responses such as more frequent blinking, change in heart rate, blood pressure, respiration, and skin conductivity, etc., making possible the use of lie detector devices. Not only lying but also hiding information increases the experience of fatigue and negatively affect task persistence and performance. ${ }^{29}$

Many everyday practices and unquestioned traditions are a good illustration of the innate predisposition to process information in symbolic terms.$^{30}$ In analogy with fetishism in animist cultures that attribute transcendent and inherent values to objects, modern humans ascribe agency, intrinsic qualities, or powers to various objects, for example, to a national flag. It is never treated as just a piece of cloth and requires ritualized ways of folding, saluting and raising it. ${ }^{31}$ When a symbol becomes identified with

\footnotetext{
27 Tambiah, S. J. (June 1968). "The Magical Power of Words". Man. 3 (2): 175-208. doi:10.2307/2798500. JSTOR 2798500

28 Id

29 Michael L. Slepian, Nir Halevy, Adam D. Galinsky The Solitude of Secrecy: Thinking About Secrets Evokes Goal Conflict and Feelings of Fatigue Michael L. Slepian, Nir Halevy, Adam D. Galinsky https://doi.org/10.1177/0146167218810770

30 Carl Jung, Man and his Symbols (1978) pp. 75-82

${ }^{31}$ Bell, Catherine (1997). Ritual: Perspectives and Dimensions. New York: Oxford University Press. pp. $156-57$.
} 
something else to which it refers, it becomes idolatrous as the symbol is taken for reality. The symbol itself is substituted for the deeper meaning it intends to convey. ${ }^{32}$ It always points beyond itself to something that is transcendent and inexplicable; opening up another dimension of reality itself. ${ }^{33}$

The symbolic culture, therefore, is instrumental to the origin of language. At the same time, the notion that language is subsidiary to symbolic culture is the equivalent of suggestion that peacock's fitness is secondary to its tail. The evolutionary advantages of language outweigh other benefits caused by anatomical and behavioral changes that differentiate modern humans from other primates and it is very unlikely that language could be subsidiary to any of them.

As Oscar Wilde states "language, is the parent, and not the child, of thought." ${ }^{34}$ However thought has another parent as well - the innate predisposition to process information in symbolic terms.

32 Tillich, Paul (1964). Theology of Culture. Oxford University Press. pp. 54. ISBN 0195007115.

33 Id

${ }^{34}$ Oscar Wilde, The Critic as Artist 